\title{
Primary bladder schwannoma: a case report and literature review
}

\author{
Yanlong $\mathrm{Xu}^{\wedge}$, Junlong Liu^, Chuize Kong, Shuqi Du^ \\ Department of Urology, The First Hospital of China Medical University, Shenyang, China \\ Correspondence to: Professor Shuqi Du. Department of Urology, The First Hospital of China Medical University, 155 Nanjing North Street, \\ Shenyang, Liaoning 110001, China. Email: shuqi_du@163.com.
}

\begin{abstract}
Primary bladder schwannoma is an extremely rare bladder tumor that originates from Schwann cells in the nerve sheath and often associated with von Reichnhausen's disease. Isolated cases of urinary bladder schwannoma are incredibly rare with no more than 1/1,000 of bladder tumours. We report a 33-year-old female patient who did not have any symptoms and was found by computed tomography (CT). Preoperative cystoscopy revealed a large sessile and smooth-surfaced mass on the anterior top of the bladder. Then she was successfully managed by partial cystectomy. Hematoxylin-eosin (HE) staining and immunohistochemistry (IHC) confirmed the mass was schwannoma. She was discharged 16 days after admission. In addition, she was followed up without intravesical recurrence or metastases for 29 months. Subsequently, literatures in PubMed (https://pubmed.ncbi.nlm.nih.gov/) accessed to bladder schwannoma since 1993 are searched and reviewed, more clinical data are provided to better assist in the diagnosis and treatment. In summary, bladder schwannoma is a rare benign tumor of the urinary system. Imaging examination and cystoscopy have a hint on the disease to a certain extent. The first choice of treatment is surgical resection, pathology is the gold standard and S-100 is usually positive. On account of the possibility of malignant transformation of the disease, Long-term follow-up is necessary.
\end{abstract}

Keywords: Bladder schwannoma; pathology and immunohistochemistry; case report

Submitted Jan 30, 2021. Accepted for publication Apr 16, 2021.

doi: $10.21037 /$ tcr-21-200

View this article at: https://dx.doi.org/10.21037/tcr-21-200

\section{Introduction}

In the United States, a total of 81,400 new cases are increased with 17,980 deaths due to bladder cancer in 2020 (1). The most common bladder tumor is urothelial carcinoma. On the contrary, bladder interstitial tumor is relatively rare. Primary bladder schwannomas accounts for $0.1 \%$ of all bladder tumors (2). Schwannomas remain the most common ones in the head and neck (40-50\%) (3), which could appear anywhere in the body where nerve sheath exists. However, schwannomas of the bladder are extremely infrequent. In the current study, we present the following article in accordance with the CARE reporting checklist (available at https://dx.doi.org/10.21037/ tcr-21-200).

\section{Case presentation}

A 31-year-old female patient had a miscarriage due to scar pregnancy and a bladder mass was found by preoperative CT examination. One month after the operation, she came to our department. She did not show any lower urinary tract symptoms and hematuria. Her physical examination and laboratory data were also alright. Posterior flexible cystoscope revealed a $3.5 \mathrm{~cm} \times 2.0 \mathrm{~cm}$ mass on the anterior top of the bladder (Figure 1A). Further computed tomography urography (CTU) was performed, demonstrating that the mass was enhanced, protruding to the bladder. The CT value of plain scan was $41 \mathrm{HU}$ and the CT value of enhanced scan was $79 \mathrm{HU}$ (Figure 1B). The patient has no basic diseases such as hypertension, coronary

^ ORCID: Yanlong Xu, 0000-0002-4492-6441; Junlong Liu, 0000-0001-5277-0996; Shuqi Du, 0000-0001-8347-601X. 

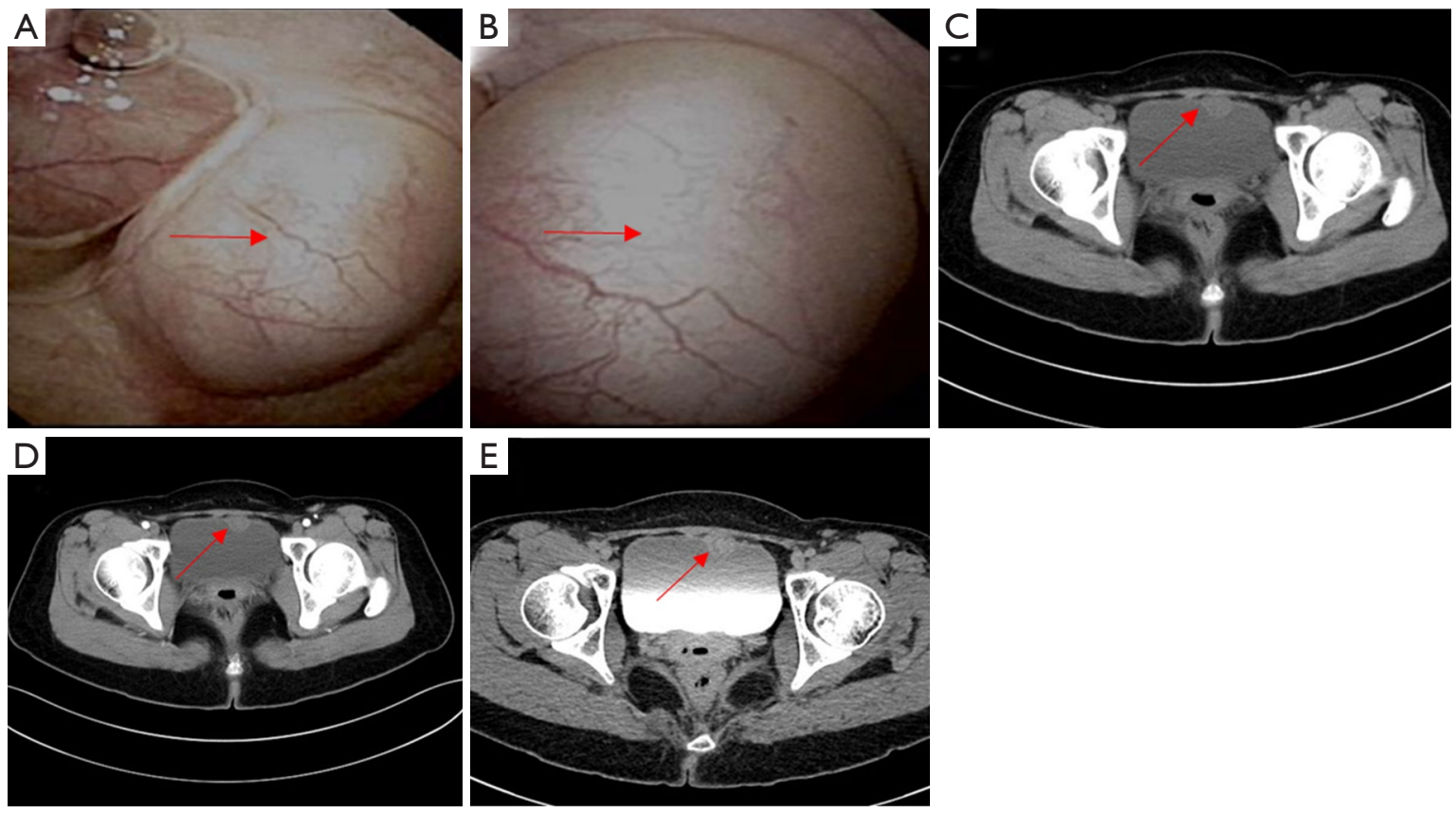

Figure 1 Preoperative examination. (A,B) Flexible cystoscope revealed a $3.5 \mathrm{~cm} \times 2.0 \mathrm{~cm}$ mass on the anterior top of the bladder. (C) Non-contrast CT showed a slightly high-density mass with a CT value of $41 \mathrm{HU}$. (D) Enhanced CT demonstrated the mass was slightly enhanced with a CT value of 79. (E) The mass can also be seen in the excretory period. Arrows indicate the location of the tumor.

heart disease and diabetes with no family hereditary history and no mental illness. Preoperative CT evaluation did not find the evidence of metastasis in both lungs and abdominal organs. Then, the patient underwent a partial cystectomy. In the surgery, we chose a lower abdominal median incision to expose the bladder step by step. A tough mass could be observed on the anterior top when opening the bladder. The tumor was completely removed with a $1 \mathrm{~cm}$ safety margin. Intraoperative freezing indicates that the safety margin is negative and the section of the excised mass was incanus. The retropubic drainage tube and catheter were removed 7 and 8 days after the operation respectively. In addition, the patient achieved good recovery and was discharged one day later. Microscopically, the tumor cells were densely arranged in bunches and palisades, the nuclei were deeply stained and the local arrangement was loose (Figure 2A,B). Subsequent immunohistochemistry (IHC) was done which showed diffuse immunoreactivity for S-100 (Figure 2C), Vimentin was simultaneously positive (Figure $2 D$ ), but other markers including smooth muscle actin (SMA) (Figure 2E), Ki-67 was $8 \%$ (Figure $2 F$ ), desmin, cytokeratin, CD68 and beta-catenin were negative., the diagnosis of schwannoma was confirmed. After 29 months of postoperative followup, as indicated by cystoscopy and urinary color ultrasound
(Figure 3A,B,C), no metastases or recurrences were observed (Figure 4). All procedures performed in studies involving human participants were in accordance with the ethical standards of the institutional and/or national research committee(s) and with the Helsinki Declaration (as revised in 2013). Written informed consent was obtained from the patient.

\section{Discussion and review of the literature}

\section{Epidemiology and origin}

The earliest case of schwannoma of the bladder was reported in 1993, which was presented as a pelvic mass (4). Schwannoma is a slow-growing myelinated nerve tumor that originates from Schwann's cells and is often associated with von Reichnhausen's disease. It usually occurs in the head and neck while bladder schwannoma is extremely infrequent and more common between the ages of 40 and 60 years (5). We searched the PubMed database. Up to 2020, there were 16 cases of bladder schwannoma. Given its rarity, we reported this case and reviewed the previous literature concerning bladder schwannoma (Table 1), including the reported years, regions, and clinical features. 

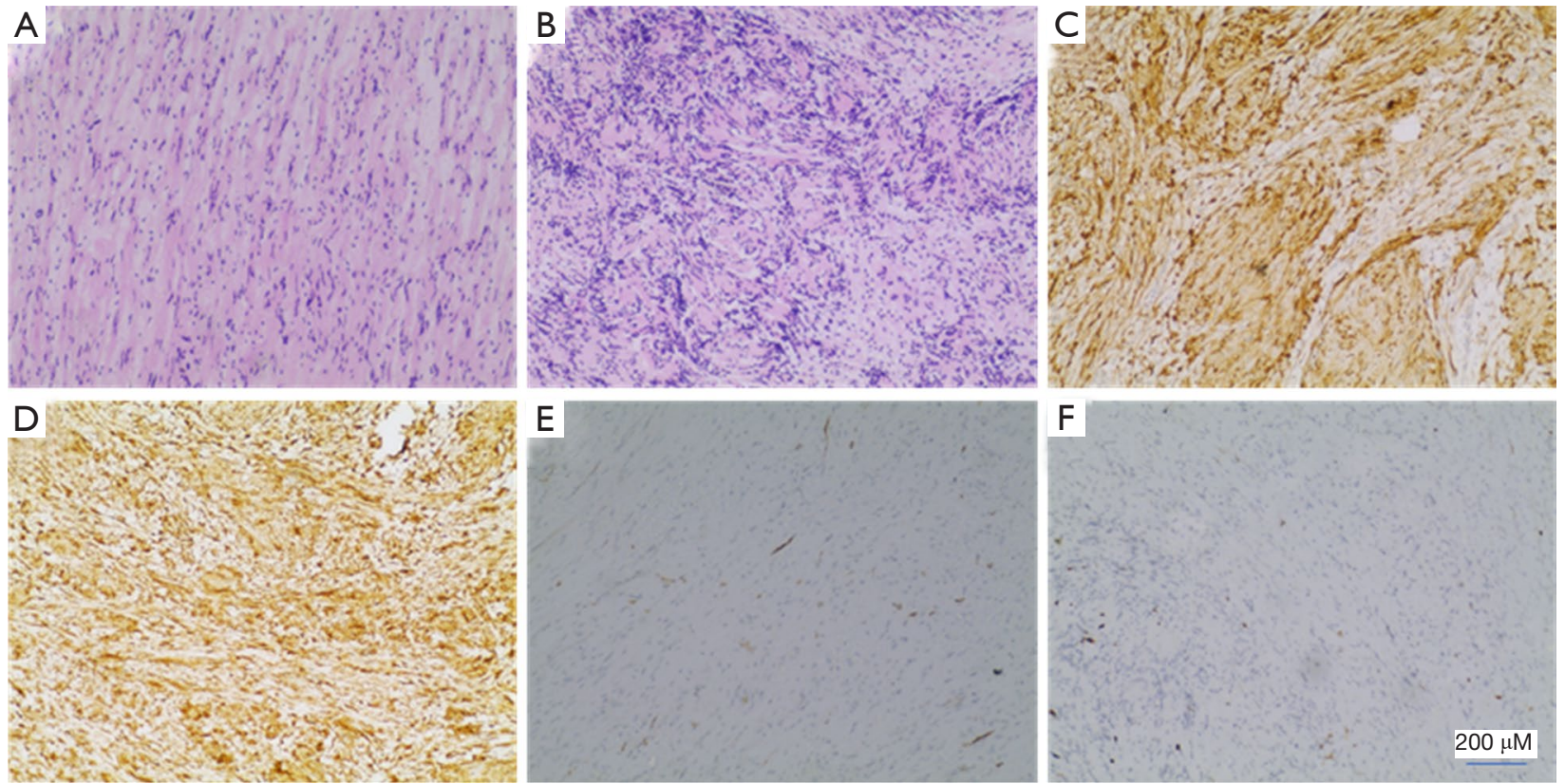

Figure 2 Histological findings of the tumor. (A,B) Hematoxylin and eosin staining indicating the tumor cells were densely arranged in bunches and palisades, the nuclei were deeply stained and the local arrangement was loose $(\times 200)$. (C) Immunohistochemistry positive for S-100 (×200); (D) Positive for Vimentin (×200); (E) Negtive for SMA (×200); (F) Positive for ki-67 (8\%) $(\times 200)$.
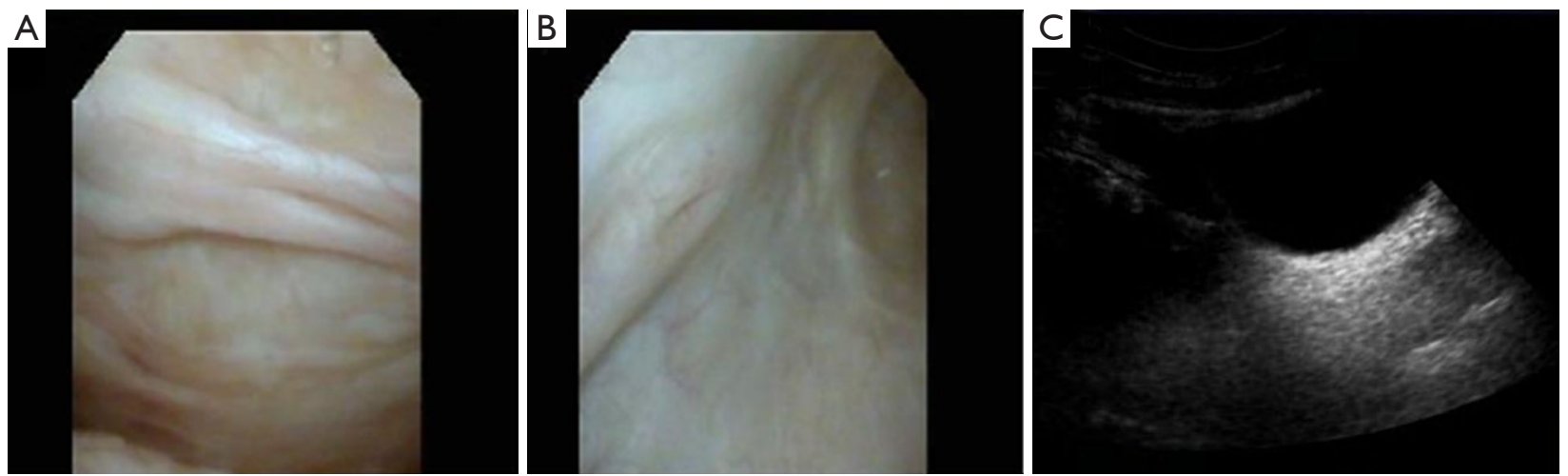

Figure 3 Postoperative reexamination. (A,B) Cystoscope showed postoperative scar (C) Urinary color ultrasound was normal.

Based on the above discussion, the most frequently reported cases were in the United Kingdom and the United States. With an average age of 49 and a median age of 50, the age of onset was between 25 and 88 . There were 7 males and 10 females, revealing no significant gender difference.

\section{Diagnosis}

The most common clinical manifestations included lower urinary tract symptoms, for instance, pain, urgency and frequency $(7 / 17,41 \%)$, followed by hematuria $(6 / 17,35 \%)$,
Dyspareunia (1/17, 5\%), vomiting $(1 / 17,5 \%)$ and recurrent infection $(1 / 17,5 \%)$. In addition, 5 cases were found accidentally. With an average of $4.4 \mathrm{~cm}$, the size of the tumor ranged from 0.8 to $20 \mathrm{~cm}$. Most tumors are found by ultrasound (US). US can be used as a bladder spaceoccupying screening due to its low price, convenience, and non-invasive characteristics. It is a pity that ultrasound was not performed in our case. Our case was detected by CT. CT showed single, intact, non-calcified and spaceoccupying lesions in the bladder area, showing isodensity or low density compared with muscle. Our case conforms 


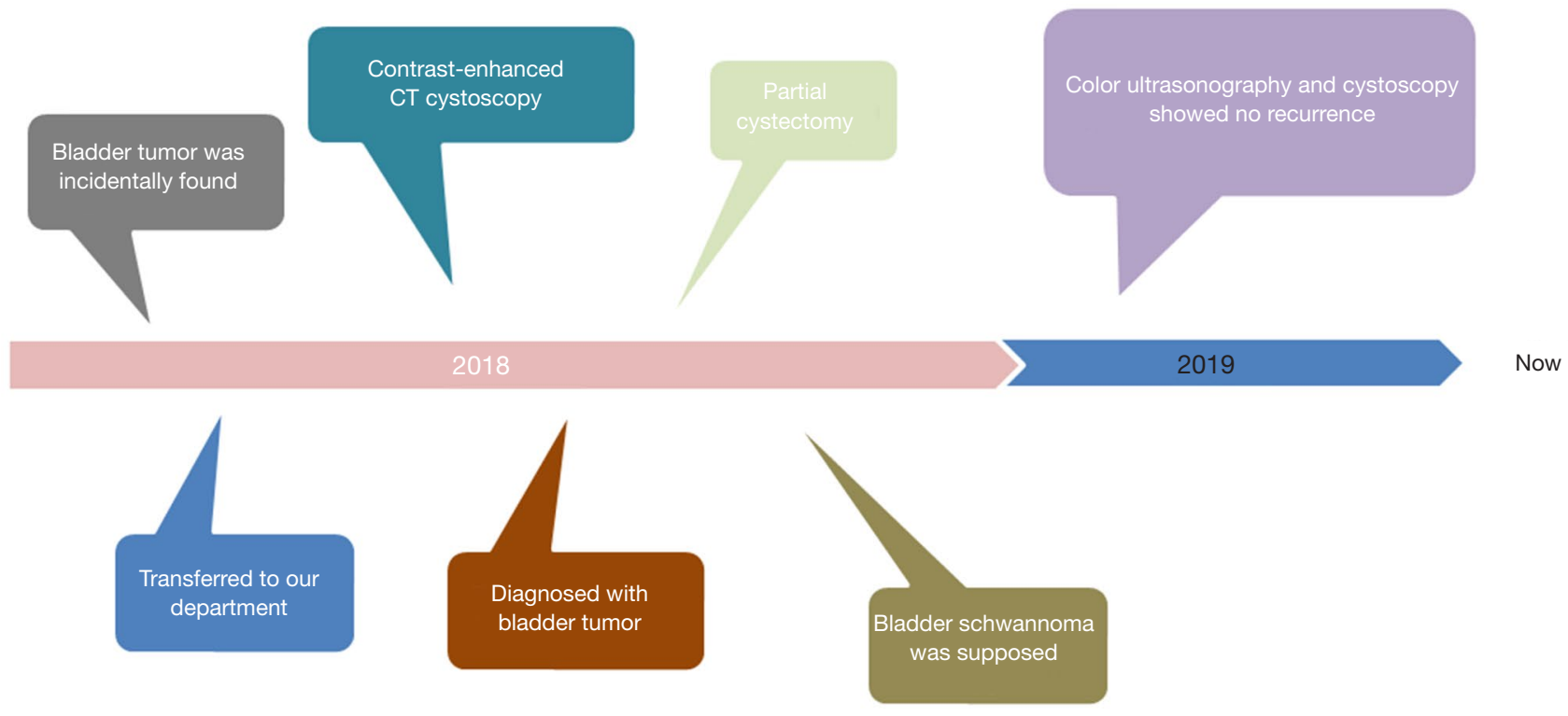

Figure 4 Timeline of interventions and outcomes.

to the above characteristics (8). On magnetic resonance imaging (MRI) scan, schwannoma presented iso-signal on T1-weighted images and slightly high signal on T2weighted images (18). Imaging examination can not be used as a specific examination for differentiating schwannoma from other solid tumors. The cystoscopic appearance is mostly solid mass, and its surface is usually smooth, which shows significant difference from the common urothelial carcinma. We consider that it has some significance in differential diagnosis. Pathology served as the gold standard for the diagnosis of the disease. Histologically, the iconic areas of Antoni A are also known as fasciculate area where the boundary of the cell is unclear, the nucleus is slender or oval, and the fusiform cells are closely arranged in bundles or incomplete spirals. Antoni B is also known as the reticular area, which is loosely arranged in the stroma by a small number of messy fusiform cells. Immunohistochemically, $\mathrm{S}-100$ is a characteristic marker of schwannoma, which is usually positive (19).

\section{Treatment and prognosis}

Surgery is the first choice for the treatment, including transurethral resection of bladder tumor (TURBT) or partial resection. We believe that some positions that can be reached by electroendoscopy such as the bladder neck, the top or the lateral wall of the bladder are suitable for TURBT. Otherwise, partial cystectomy is recommended.
Almost all patients did not have recurrence except for the case Georgiadis $\mathrm{G}$ reported. The patient received TURBT and relapsed 6 months after surgery. Due to no symptoms and personal reasons, the patient was untreated, the tumor was removed again after 12 months, and the histological diagnosis confirmed residual peripheral nerve sheath tumour. Subsequent follow-up showed the tumor regrowth and conservative treatment was chosen with regular followup (7). In addition, radiotherapy can also be used as an attempt $(10,12)$. It has been reported that chemotherapy is invalid to extracranial schwannoma (9). However, a patient in France received TURBT plus Botulinum toxin (botox). To our knowledge, this is the first case treated by intravesical instillation of Botox. The patient's clinical symptoms were improved. Follow-up urine cytology and pelvic MRI were normal. Moreover, this management strategy is worthy of further investigations (15). Our article comprehensively analyzed the clinical data of totally 16 patients reported in PubMed database. The follow-up period was 1.5 to 48 months.

\section{Conclusions}

The clinical feature of bladder schwannoma is not specific. In the meanwhile, imaging is difficult to distinguish from other bladder tumors. Although the shape under cystoscope has a certain hint on the disease, pathological examination is the exact standard for diagnosis. Due to the infrequent 
Table 1 Reported cases of bladder schwannoma

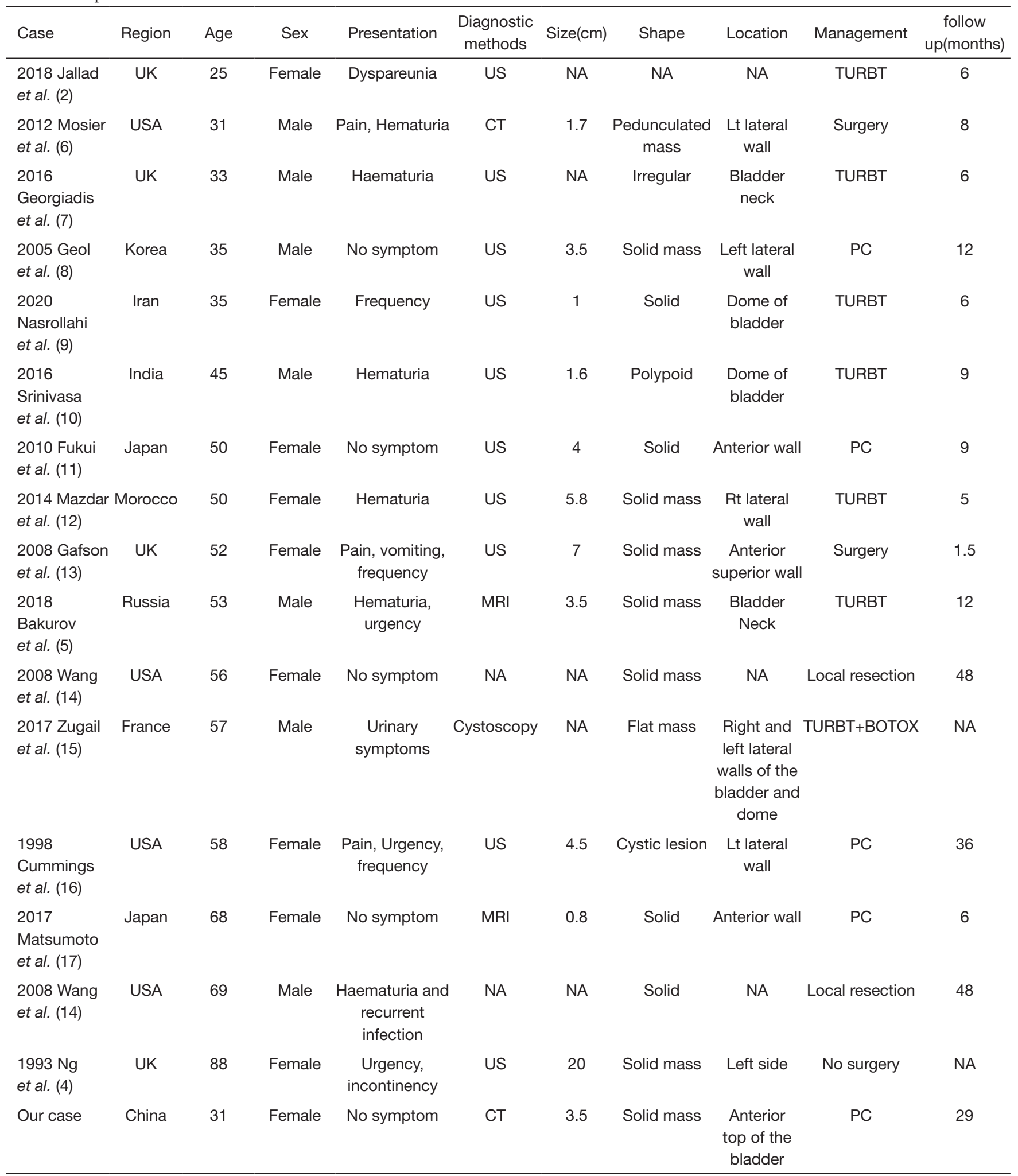

TURBT, transurethral resection of bladder tumor; PC, partial cystectomy; US, ultrasonography; NA, not available; CT, computed tomography; MRI, magnetic resonance imaging; LT, left; RT, right. 
clinical cases of bladder schwannoma, the lack of large samples and systematic research statistics, there is no unified therapeutic schedule up to the present. On account of the possibility of malignant transformation of the disease, surgical resection is the current preference. Long-term follow-up after operation is also indispensable.

\section{Acknowledgments}

We thanked Muscab Soyan [native speaker (United Kingdom)] for the proofreading of the paper.

Funding: None.

\section{Footnote}

Reporting Checklist: The authors have completed the CARE reporting checklist. Available at https://dx.doi. org/10.21037/tcr-21-200

Peer Review File: Available at https://dx.doi.org/10.21037/ tcr-21-200

Conflicts of Interest: All authors have completed the ICMJE uniform disclosure form (available at https://dx.doi. org/10.21037/tcr-21-200). The authors have no conflicts of interest to declare.

Ethical Statement: The authors are accountable for all aspects of the work in ensuring that questions related to the accuracy or integrity of any part of the work are appropriately investigated and resolved. All procedures performed in studies involving human participants were in accordance with the ethical standards of the institutional and/or national research committee(s) and with the Helsinki Declaration (as revised in 2013). Written informed consent was obtained from the patient.

Open Access Statement: This is an Open Access article distributed in accordance with the Creative Commons Attribution-NonCommercial-NoDerivs 4.0 International License (CC BY-NC-ND 4.0), which permits the noncommercial replication and distribution of the article with the strict proviso that no changes or edits are made and the original work is properly cited (including links to both the formal publication through the relevant DOI and the license). See: https://creativecommons.org/licenses/by-nc-nd/4.0/.

\section{References}

1. Siegel RL, Miller KD, Jemal A. Cancer statistics, 2020. CA Cancer J Clin 2020;70:7-30.

2. Jallad S, Ghani S, Omar MA, et al. Isolated bladder schwannoma: a rare presentation. BMJ Case Rep 2018;2018:bcr2017223154.

3. Xu SY, Wu YS, Li JH, et al. Successful treatment of a pancreatic schwannoma by spleen-preserving distal pancreatectomy. World J Gastroenterol 2017;23:3744-51.

4. $\mathrm{Ng} \mathrm{KJ}$, Sherif A, McClinton S, et al. Giant ancient schwannoma of the urinary bladder presenting as a pelvic mass. Br J Urol 1993;72:513-4.

5. Bakurov EE, Krakhotkin DV, Kucherenko OB. Isolated primary schwannoma of the urinary bladder- a case presentation. Urol Case Rep 2018;18:29-30.

6. Mosier AD, Leitman DA, Keylock J, et al. Bladder schwannoma - a case presentation. J Radiol Case Rep 2012;6:26-31.

7. Georgiadis G, Bonatsos V, Koulouris A, et al. Isolated peripheral nerve sheath tumour involving the urinary bladder neck. J Clin Urol 2016;9:59-61.

8. Geol H, Kim DW, Kim TH, et al. Laparoscopic partial cystectomy for schwannoma of urinary bladder: case report. J Endourol 2005;19:303-6.

9. Nasrollahi H, Ariafar A, Ahmed F, et al. Isolated schwannoma of the urinary bladder: a case report and review of the literature. Pan Afr Med J 2020;35:108.

10. Srinivasa $Y$, Bhat $S$, Paul F. Isolated Primary Schwannoma of Urinary Bladder. J Clin Diagn Res 2016;10:PD12-3.

11. Fukui S, Kiba K, Shinohara M, et al. Schwannoma arising from the urinary bladder wall: a case report. Hinyokika Kiyo 2010;56:513-6.

12. Mazdar A, Asseban M, Aboussalah H, et al. Schwannoma of the urinary bladder: a case report. Pan Afr Med J 2014;18:84.

13. Gafson I, Rosenbaum T, Kubba F, et al. Schwannoma of the bladder: A rare pelvic tumour. J Obstet Gynaecol 2008;28:241-3.

14. Wang W, Montgomery E, Epstein JI. Benign nerve sheath tumors on urinary bladder biopsy. Am J Surg Pathol 2008;32:907-12.

15. Zugail AS, Benadiba S, Ferlicot S, et al. Oddities Sporadic Neurofibroma of the Urinary Bladder. A Case Report. Urol Case Rep 2017;14:42-4.

16. Cummings JM, Wehry MA, Parra RO, et al. Schwannoma of the urinary bladder: a case report. Int J 
Urol 1998;5:496-7.

17. Matsumoto Y, Waku N, Kawai K, et al. A Case of Primary Schwannoma of the Urinary Bladder. Hinyokika Kiyo 2017;63:323-8.

18. Murovic JA, Kim DH, Kline DG. Neurofibromatosis-

Cite this article as: $\mathrm{Xu} \mathrm{Y,} \mathrm{Liu} \mathrm{J,} \mathrm{Kong} \mathrm{C,} \mathrm{Du} \mathrm{S.} \mathrm{Primary}$ bladder schwannoma: a case report and literature review. Transl Cancer Res 2021;10(6):3067-3073. doi: 10.21037/tcr-21-200 associated nerve sheath tumors. Case report and review of the literature. Neurosurg Focus 2006;20:E1.

19. Pytel P, anthony DC. Peripheral nerves and skeletal muscles. Robbins and Cotran pathologic basis of disease. 9th ed. Philadelphia: Elsevier Saunders, 2015:1246-9. 